\title{
The function of tumour necrosis factor and receptors in models of multi-organ inflammation, rheumatoid arthritis, multiple sclerosis and inflammatory bowel disease
}

\author{
George Kollias, Eleni Douni, George Kassiotis, Dimitris Kontoyiannis
}

\begin{abstract}
There is now good evidence to demonstrate that aberrations in tumour necrosis factor (TNF) production in vivo may be either pathogenic or protective and several plausible mechanisms may explain these contrasting activities. According to the classic pro-inflammatory scenario, failure to regulate the production of TNF at a site of immunological injury may lead to chronic activation of innate immune cells and to chronic inflammatory responses, which may consequently lead to organ specific inflammatory pathology and tissue damage. However, more cryptic functions of this molecule may be considered to play a significant part in the development of TNF mediated pathologies. Direct interference of TNF with the differentiation, proliferation or death of specific pathogenic cell targets may be an alternative mechanism for disease initiation or progression. In addition to these activities, there is now considerable evidence to suggest that TNF may also directly promote or down regulate the adaptive immune response. A more complete understanding of the temporal and spatial context of TNF/TNF receptor (TNF-R) function and of the molecular and cellular pathways leading to the development of TNF/TNF-R mediated pathologies is necessary to fully comprehend relevant mechanisms of disease induction and progression in humans. In this paper, the potential pathogenic mechanisms exerted by TNF and receptors in models of multi-organ inflammation, rheumatoid arthritis, multiple sclerosis and inflammatory bowel disease are discussed. Elucidating the nature and level of contribution of these mechanisms in chronic inflammation and autoimmunity may lead to better regulatory and therapeutic applications.

(Ann Rheum Dis 1999;58:(Suppl I) I32-I39)
\end{abstract}

Laboratory of Molecular Genetics, Hellenic Pasteur Institute, 127 Vas Sofias Avenue, Athens 115 21, Greece

Correspondence to: Dr G Kollias.
Tumour necrosis factor (TNF) is produced in response to infection or immunological injury and effects multiple responses, which extend beyond its well characterised proinflammatory properties $^{1}$ to include diverse signals for cellular differentiation, proliferation and death. ${ }^{2}$ Part of the complexity of TNF mediated responses may be related to the apparent differential bioactivities of its soluble and transmembrane form ${ }^{3}$ and the differential functioning of its two tumour necrosis factor receptors (TNF-Rs). ${ }^{2}$ TNF has been for many years at the apex of factors showing dominant contribution to disease pathogenesis, especially chronic inflammation and autoimmunity. Its in vitro activities are now well understood and the signals transduced by the two TNF-Rs have been sufficiently detailed both at the molecular and the cellular level. However, the specific role of TNF and receptors in disease pathogenesis remains still poorly defined. Data discussed in this review, point towards multiple in vivo activities for this molecule. Firstly, the potent innate inflammatory activities of TNF seem central to disease induction and progression, particularly when sustained TNF expression is provoked. Evidence for direct effects of TNF on non-immune stromal cell types, which are important for the function of a given tissue or organ, is also available, and may offer alternative mechanisms for pathogenic contribution. Lastly, more recent data indicating direct modulation by TNF of the adaptive immune response may also be taken into consideration, to explain the beneficial or at times detrimental role of TNF in spontaneous models of autoimmunity. It is evident that no unique scenario is available to explain the role of TNF in inflammatory or autoimmune pathology. Rather, a diverse range of activities is expected to function in each model case, and most probably also in human disease. In figure 1, we have summarised the factors affecting $\mathrm{TNF} /$ TNF-R function in disease. Obviously, the diverse in vivo functions of TNF may significantly depend on the duration, quantity and quality of TNF signals. In addition, genetic background, locality and timing of TNF expression may also modulate the function of this molecule and diversify the end result of the immune response, either to the benefit or distress of the host. Experimental modification of these parameters in transgenic and knockout animal models of TNF mediated disease has been revealing.

\section{Role of TNF in models of rheumatoid} arthritis (RA)

The majority of the joint inflammatory disorders, typified by the manifestations of RA, are characterised by the hyper-proliferation of synovial tissue and the infiltration of blood derived cells resulting in the progressive erosion of the cartilage and bone. Genetic sus- 


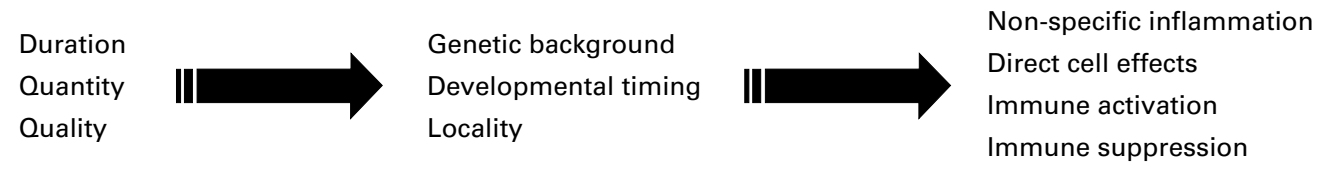

Figure 1 The diverse in vivo functions of TNF may significantly depend on the duration, quantity and quality of TNF signals. In addition, genetic background, locality and timing of TNF expression may also modulate the function of this molecule and diversify the end result of the immune response, either to the benefit or distress of the host.

ceptibility, physical stress, infectious agents and aberrant immune responses have all been implicated in the pathogenesis of RA. ${ }^{4}$ The increased genetic linkage of specific HLA-DR haplotypes with $\mathrm{RA}^{5}$ and the presence of experimental models of RA, induced in genetically susceptible animals after immunisation with collagen, led to the original assumption of autoimmune mechanisms playing a dominant part in both the induction and maintenance of the disease. However, the contribution of adaptive mechanisms in the pathogenesis of RA could not be confirmed at the clinical level, as both anti-CD4 and anti-CD5 clinical trials failed to induce a beneficial outcome. ${ }^{67}$

The role of lymphocytes in driving the arthritogenic response in the popular animal model of collagen induced arthritis (CIA) has also recently been challenged. Although $\mathrm{T}$ cell transfers and antibody depleting studies ${ }^{8-10}$ had previously established the pathogenic potential of specific antigen reactive cells in this model, administration of collagen type II in CD4- and CD8-deficient mice resulted in the appearance (albeit with lower incidence) of the typical CIA profile, failing to provide evidence for an essential role in disease induction. ${ }^{11}$ In view of the conflicting evidence on the role of an adaptive pathogenic immune response in CIA, we recently backcrossed Rag-1 deficient mice lacking mature lymphocytes into the CIA susceptible DBA/1 genetic background. ${ }^{12}$ Collagen type II immunisation of these mice resulted in the development of arthritic lesions in their joints characterised by synovial hyperplasia with occasional inflammation as well as cartilage and bone destruction. The observed delayed onset and reduced severity of disease suggests that lymphocytes do play a significant, yet secondary part in disease induction. Evidence of synoviocyte proliferation in the absence of inflammation, after collagen administration in the DBA/1-immunodeficient mice, indicated an immediate responsiveness of this cell type to collagen. It may therefore be suggested that in susceptible genetic backgrounds, sequestration of collagen resulting from insults affecting joint integrity may activate the synoviocyte and cause pathology. These, non-antigenic properties of collagen may offer new clues as to the mechanisms operating in the pathogenesis of RA.

Early detection of a broad range of proinflammatory cytokines in RA biopsy specimens and explant cultures, established their importance in joint inflammation. ${ }^{4}$ Among them, the significance of TNF in mediating the arthritogenic response, has been demonstrated by the amelioration of arthritic lesions in antiTNF treated animal models of arthritis ${ }^{13}{ }^{14}$ and most importantly in human disease. ${ }^{4}$ Perhaps, the most informative animal model, as to the TNF mediated mechanisms operating in arthritis, has been produced by the introduction of modified human TNF transgene in mice. ${ }^{15}$ Based on the possible role of TNF 3'UTR on the translational repression of TNF mRNA, this region was replaced by that of the $\beta$-globin gene. The resulting transgenic mice developed a form of erosive arthritis with similar histological characteristics to RA. A similar form of arthritis appeared also in targeted mutant mice lacking the 3'AU-rich elements (TNF ${ }^{\triangle A R E}$ mutant mice), confirming the role of these elements in the maintenance of a physiological TNF response in the joint. ${ }^{16}$ In addition, neutralisation of arthritis by treatment of the hTNF transgenic mice with antibodies against TNF or the type I IL1 receptor established the idea that a functional hierarchy exists, in which the IL1R acts in series and downstream of TNF to effect TNF mediated arthritogenic responses. ${ }^{17}$

Absence of the 3'ARE elements from the mRNA of TNF results in chronic polyarthritis. A proposed mechanism that may affect the pathogenic outcome in arthritis, may be the inability of natural anti-inflammatory signals to suppress the destructive TNF expression in the arthritic joint. Anti-inflammatory mediators such as IL10, IL4 and TGF- $\beta$ are abundant in rheumatoid joints, supporting the hypothesis of a counter-reaction compensating for the increased proinflammatory load. ${ }^{18} 19$ However, this equilibrating response is apparently not sufficient to block disease progression. The inability of IL10 to efficiently suppress macrophage and/or synoviocyte TNF production because of the absence of the natural TNF 3'UTR (our unpublished observations), postulate a possible involvement of mutations affecting the expression of TNF (for example, functional mutations in TNF's ARE sequences) as aetiopathogenic factors in disease initiation or progression. This is further suggested by the fact that treatment of hTNF3'globin transgenic mice with cellular vectors producing IL4, IL10 and IL13 did not significantly affect development of arthritis in this model. ${ }^{20}$ The minimal, if any, role of adaptive immunity in the development of arthritis in these models has been confirmed in studies demonstrating that the course of disease in hTNF transgenic and $\mathrm{TNF}^{\triangle \mathrm{ARE}}$ mutant mice is not affected by the absence of mature T and B cells. ${ }^{1621}$ This is in agreement with transplantation studies showing destruction of human cartilage by RA derived synoviocytes engrafted in the kidney capsule of SCID mice. ${ }^{22}{ }^{23}$

Perhaps most importantly, the ARE deletion results in a profound spontaneous capacity of synoviocyte fibroblasts to produce $\mathrm{TNF}^{1621}$ 
Synoviocytes have been considered pivotal for the development of the arthritic reaction as they proliferate in response to $\mathrm{TNF}^{24}$ and produce extracellular matrix-degradative enzymes and chemokines. ${ }^{25} 26$ Their capacity to also produce TNF as a result of an ARE deletion, underscores their central role as both target and effector cells capable of initiating and maintaining the arthritogenic response. In an effort to assess if the TNF expressing synovial fibroblast is sufficient to induce disease, we have recently transferred clones of hTNF expressing synovial fibroblasts into the knee joint of histocompatible normal recipients. Migration of such fibroblasts from the injection site into other joints and different organs of the mouse could be demonstrated. Furthermore, four weeks after engraftment, a percentage of the mice developed polyarthritis with all the basic characteristics described for the donor (David Plows, Sylva Haralambous and George Kollias, unpublished observations). Interestingly, synoviocytes are seen to behave like tumour cells and can readily invade and destroy the environment that they home into. ${ }^{27}$ In this context, the migration and homing of transferred TNF transgenic synoviocytes into multiple joints of recipient mice can be viewed as a metastatic process and the capacity to form a tumour mass may also rely on the angiogenic activities of TNF.

In conclusion, in models of TNF mediated arthritis, conceivably also in RA, the most critical phenomenon for both the initiation and perpetuation of disease seems to be the capacity of TNF to transform the nature of the synovial fibroblast, a cell with immense potential for unrestricted proliferation and autonomous invasion into the cartilage or bone. In this context, the contribution of non-specific inflammation and adaptive immunity seems to be in the regulation rather than initiation of disease. Understanding further the biology of the synovial fibroblast may offer new clues on additional molecules and mechanisms playing critical parts in the pathogenesis of arthritic disease.

\section{Role of TNF in models of inflammatory bowel disease (IBD)}

Pathogenesis of idiopathic IBD has been closely associated with the altered production of several pro-inflammatory cytokines. More specifically, the correlation between increased TNF production and IBD development has been exemplified in several animal models for this disease via the use of specific neutralising antibodies or cytokine gene knockouts. ${ }^{28-30}$ Most convincing, the central role of TNF in the pathophysiology of human Crohn's disease (CD) has been overtly confirmed in clinical trials using a single dose of anti-TNF monoclonal antibody in patients with treatment refractory $\mathrm{CD} .{ }^{31}$ Furthermore, a similar to the human form of IBD appeared also in targeted mutant mice lacking the 3'AU-rich elements, ${ }^{16}$ further substantiating the role of TNF in the development of diseases affecting the gut. The gut histopathological characteristics of the $\mathrm{TNF}^{\triangle \mathrm{ARE}}$ mice, including transmural inflamma- tion, granuloma formation and ileal confinement, most closely resemble the human condition of $\mathrm{CD}^{32}$ providing, for the first time positive evidence for TNF in inducing this form of IBD. ${ }^{16}$

TNF action in IBD has been considered mainly inflammatory through the activation of endothelial cells, induction of chemokines, and recruitment of neutrophils in the gut mucosa. ${ }^{33}$ TNF has been shown to influence intestinal epithelial cell growth, ${ }^{34}$ permeability, ${ }^{35}$ and integrity via matrix metalloproteinase (MMP) production $^{36}$ and to induce epithelial cell apoptosis. ${ }^{37}$ In addition, TNF has been implicated in the formation of bacterial induced granulomas through the induction of MCP-1 production by endothelial cells. ${ }^{38}$ Intestinal epithelial damage is considered an early histopathological manifestation in $\mathrm{CD}^{39}$ supporting the assumption that TNF plays a central part in initiating mucosal events in IBD. However, the action of TNF in the $\mathrm{TNF}^{\triangle \mathrm{ARE}}$ model of CD does not seem to be solely of an innate pro-inflammatory character. Intestinal pathology in these mice is heavily dependent on the presence of mediators or cells of the adaptive immune response, because in the absence of mature lymphocytes (for example, in backcrosses to Rag-1 deficient mice) intestinal inflammation is neutralised. ${ }^{16}$ It is therefore possible that the chronic TNF production resulting from the ARE deletion shapes up a pathogenic lymphocytic response. TNF production has been numerously suggested to drive pathogenic Th1-like responses in concert with both IL12 and IFN $\gamma^{40-44}$ Interestingly, activated mucosal $\mathrm{T}$ cells from $\mathrm{CD}$ patients demonstrate a characteristic Th 1 cytokine profile associated with active disease. ${ }^{45}$ Furthermore, a significant reduction of Th1-like lamina propria mononuclear cells has been reported in CD patients treated with the cA2 anti-TNF antibody, suggesting that anti-TNF treatment may proceed through the down regulation of mucosal Th1 cytokines. ${ }^{46}$

Our observation that in $\mathrm{TNF}^{\triangle \mathrm{ARE}}$ mice, IBD progression is also dependent on the function of the p75TNF-R, a receptor that is expressed mainly on hemopoietic cells, raises the intriguing possibility that TNF overproduction modulates the pathogenic response via the utilisation of this receptor. A suggested mechanism to explain disease pathogenesis in murine IBD has been provided by the CD4+ $\mathrm{T}$ cell transfer model of colitis. ${ }^{29}$ In this model a $\mathrm{T}$ helper cell population (CD4+CD45RB $\left.{ }^{\text {high }}\right)$ isolated from healthy mice, elicits an aggressive from of colitis upon transfer to SCID mice. Anti-TNF/IFN $\gamma$ treatment ameliorates disease progression indicating that this population elicitis pathogenic Th1 responses. In addition, a counteracting $\mathrm{T}$ regulatory population $\left(\mathrm{CD} 4+\mathrm{CD} 45 \mathrm{RB}^{\mathrm{low}}\right)$ can suppress disease induction upon co-transfer. The presence of such regulatory $\mathrm{T}$ cell subsets in gut mucosa indicate a general homeostatic mechanism that should exist in this locality to counter balance the proinflammatory state resulting from the continuous bacterial assault from the gut lumen. Our data predict that the abnormal 
TNF production results in the activation of the pathogenic $\mathrm{T}$ cell compartment, either through pro-inflammatory mechanisms or via direct suppression of the immunomodulatory compartment. It is even more appealing to predict that engagement of the p75TNF-R is differentially providing the suppressive signal for regulatory $\mathrm{T}$ cell populations. Mechanistically, chronic TNF production can induce a state of hypo-responsiveness via attenuation of TCR signalling ${ }^{47}$ and/or induction of apoptosis. ${ }^{48} 49$

It remains unclear if localised or systemic events are necessary for the IBD phenotype to develop in the $\mathrm{TNF}^{\triangle A R E}$ mice. In many animal models of IBD, a central immunological imbalance, for example, deficiency in IL2, TCR $\alpha \beta$, or overexpression of CD3, the profound alterations in $T$ cell compartments favour the development of the disease. ${ }^{50}$ It is therefore possible, that a central (thymic) deregulation will favour the development of the disease in $\mathrm{TNF}^{\triangle A R E}$ mice. In light of what has been discussed so far, it is possible that TNF mediated dysregulation may impair the homeostatic interaction of these compartments leading to the expansion of pathogenic specificities. Further use of transgenic and mutant TNF mice as models of IBD, should allow better understanding of the intriguing activities of TNF in mucosal immunity.

\section{Role of TNF in spontaneous and antigen induced models of multiple sclerosis (MS)}

A pivotal role for $\mathrm{TNF}$ in the pathogenesis of inflammatory demyelinating disease of the central nervous system (CNS) has been suggested in several studies of MS in humans and in experimental autoimmune encephalomyelitis (EAE), an established autoimmune model for human MS. TNF is overproduced in the serum and cerebrospinal fluid of $\mathrm{MS}$ patients ${ }^{51}$ and by resident and infiltrating cell $\mathrm{s}^{52}$ at sites of CNS injury. TNF can induce selective cytotoxicity of oligodendrocytes in vitro ${ }^{53}$ and myelin damage in brain slices, ${ }^{54}$ and is therefore directly implicated in the demyelinating process. The established activities of TNF in the initiation and maintenance of local inflammation, which are mediated by its known inductive effects on adhesion molecule expression $^{55}$ and macrophage activation, ${ }^{56}$ may also contribute to the CNS lesions. In EAE, anti-TNF treatment completely prevents initiation of pathology and ameliorates the progression of established disease. ${ }^{57}{ }^{58}$ Moreover, similarly to the organ specific inflammatory phenotypes obtained in several TNF overproducing transgenic and mutant mice, ${ }^{15} 165960$ TNF overexpression in the CNS of transgenic mice has revealed the potential of this cytokine to induce an inflammatory CNS demyelinating disease ${ }^{61}{ }^{62}$ In these transgenic models, TNF triggered CNS demyelinating disease is characterised by oligodendrocyte apoptosis, primary demyelination, and lymphocyte and macrophage infiltration of the CNS, resulting in loss of neural function. ${ }^{63}$ Thorough characterisation of the demyelinating process at the histological level has validated TNF transgenic mice as accurate models for MS. ${ }^{63}$ The mechanism of action of TNF in these models is not fully defined, but it could predictably involve recruitment and activation of macrophage/ microglia, direct cytotoxicity of oligodendrocytes and/or triggering of a quiescent myelin reactive encephalitogenic component. However, removal of the mature lymphocytic population in these mice, by means of backcrossing to the immunodeficient Rag-1 knockout strain, did not change the development of primary demyelination demonstrating that TNF mediated pathology in this model does not require the adaptive arm of the immune response. ${ }^{64}$ Similar mechanisms leading to primary demyelination with minimal, if any, immune involvement might also operate in MS.

The important role of TNF in inflammatory demyelination has also been examined in TNF deficient mice generated by gene targeting in embryonic stem (ES) cells. Myelin basic protein (MBP) induced EAE in TNF deficient mice crossed to the SJL/J strain was considerably delayed compared with an SJL.H-2b congenic control or the SJL/J strain itself, ${ }^{65}$ in agreement with myelin oligodendrocyte glycoprotein (MOG) induced EAE in TNF or p55TNF-R deficient mice. ${ }^{66-68}$ However, although TNF deficiency reproducibly delays the onset of EAE in different models of the disease, severe EAE with perivascular inflammation and primary demyelination eventually develops in TNF deficient mice, ${ }^{65}{ }^{66}$ indicating that other mediators may compensate for the absence of TNF during these processes. Although a more extensive quantitative comparison of the level of demyelination in wild type and TNF deficient mice is necessary, it is evident that TNF is not an obligatory mediator in the demyelinating process. The use of MBP as immunogen for EAE induction in TNF deficient mice also allowed an assessment of the role of TNF in autoimmune $\mathrm{T}$ cell development in general. The specificity of the $\mathrm{T}$ cell response of $\mathrm{H}-2 \mathrm{~b}$ mice to MBP maps to a part of the molecule ${ }^{69}$ that is expressed in the thymus of SJL mice ${ }^{70}$ and the role of this thymic expression of MBP in T cell negative selection has recently been established. ${ }^{71}{ }^{72}$ In light of the ability of TNF to attenuate $\mathrm{T}$ cell receptor signalling, ${ }^{47}$ a prediction has been put forward ${ }^{73}$ that TNF expression imbalances in the thymus would have an effect on autoreactive $\mathrm{T}$ cell negative or positive selection. If TNF were influencing the strength of antigenic stimulation of thymocytes by a given autoantigen, it would possibly affect the susceptibility to the disease induced by this selecting autoantigen. However, analysis of the $\mathrm{T}$ cell responses of TNF deficient mice to MBP demonstrated that the avidity and the peripheral response of autoreactive T cells to MBP and the incidence and severity of MBP induced EAE in mice are not influenced by the TNF deficiency. ${ }^{65}$ This result argues against an involvement of TNF in the generation and function of MBP specific self reactive $T$ cells.

In conclusion, the important role of TNF in the development of inflammatory demyelination in the CNS has been revealed both in 
spontaneous models of transgenic TNF overexpression in the CNS and in the antigen induced EAE model. In the former, TNF is clearly shown to cause primary demyelination. In EAE, TNF deficiency is shown to delay the onset of clinical disease. Studies in knockout mice have been useful in revealing the essential properties of disrupted genes as well as their redundant functions. For example, the finding that TNF deficiency does not completely prevent the development of demyelination during EAE underscores the existence of alternative pathways of demyelination. In that sense, the concept that there may be a single immunological pathway ultimately causing pathology in MS, is probably too simplistic. The presented studies indicate the existence of at least two distinct and seemingly independent immunological pathways leading to clinically indistinguishable types of myelin pathology classified in humans as "MS". Coexistence of multiple demyelinating pathways operating in concert could also explain the apparently unsuccessful trials of anti-TNF/LTa ${ }^{74}{ }^{75}$ or, anti-CD4 treatment $^{76}$ in established MS. Alternatively, mechanisms of disease induction as seen in the animal models, suggest that anti-TNF treatments in MS may be more efficacious at earlier stages where leucocyte trafficking and non-specific inflammation should play a most critical part in the amplification and perpetuation of disease. As additional information regarding initiating factors and common mediators of these pathways will emerge, better strategies for immune intervention will be discovered.

\section{Role of the p75TNF-R in multi-organ inflammation}

The two TNF receptors are known to mediate, either in cooperation or independently, a wide spectrum of cellular responses ranging from proliferation and differentiation to cytotoxicity or apoptosis. ${ }^{27}$ In addition, soluble forms of the two TNF-Rs (sTNF-R) have been identified in biological fluids and are thought to have regulatory functions by affecting systemic TNF bioavailability. ${ }^{78}$ Although knowledge of the biochemistry of TNF-R signal transduction is quite advanced, ${ }^{79}$ understanding of the in vivo functions of the two TNF receptors remains vague. Using TNF or TNF-R knockout mice, the $\mathrm{TNF} / \mathrm{p} 55 \mathrm{TNF}-\mathrm{R}$ pair was shown to have an essential role in many physiological processes including lymphoid organ architecture, ${ }^{80} 81$ activation induced $\mathrm{T}$ cell death, ${ }^{49}$ and resistance against bacterial, ${ }^{80} 82{ }^{83}$ parasitic, ${ }^{84}$ or viral infections. ${ }^{85} \mathrm{~A}$ dominant role of the p55TNF-R has also been apparent in at least the induction phase of several TNF mediated pathologies, including endotoxemic shock in the presence of TNF sensitising agents, ${ }^{82} 83$ or in several transgenic models of disease where deregulated production of TNF has been pathogenic. ${ }^{15} 5963$ In contrast, using p75TNF-R knockout mice, there has been very little evidence for a specific involvement of the p75TNF-R in physiology or experimental models of disease. ${ }^{286}$ This failure to demonstrate an in vivo independent activity of the
p75TNF-R in the knockout system, together with ample in vitro evidence for a cooperative role of this receptor in $\mathrm{p} 55 \mathrm{TNF}-\mathrm{R}$ mediated responses, have led to the concept that the p75TNF-R serves an accessory role in increasing p55TNF-R signalling. ${ }^{87}$ It should be noted, however, that some in vivo functions of this receptor have been recently revealed in murine models of cerebral malaria, ${ }^{88}$ in concanavalin-A induced hepatitis ${ }^{89}$ and in the allergen induced migration of Langerhan's cells. ${ }^{90}$ Interestingly, so far, the in vitro activities of the p75TNF-R have always been associated with the capacity of this molecule to induce the proliferation of thymocytes and peripheral $\mathrm{T}$ cells, ${ }^{91}{ }^{92}$ but also the death of activated CD $8+\mathrm{T}$ cells. ${ }^{48}{ }^{93}$ Indeed, in contrast with the p55TNF-R, which is expressed on almost every cell type, the expression patterns of the p75TNF-R are restricted to endothelial cells and cells of haemopoietic origin, ${ }^{94}{ }^{95}$ suggesting that the in vivo activities of this molecule may only be evident in phenomena involving these specific cell types. In addition, the well documented preference of the p75TNF-R to signal upon binding to transmembrane, ${ }^{3}$ rather than soluble $\mathrm{TNF}^{96}$ may hamper attempts to identify an in vivo role for this receptor in models where soluble TNF overexpression or p55TNF-R dependent activities often dominate the ensuing phenotypes.

The independent in vivo activities of the p75TNF-R, have recently been investigated in transgenic mice that express constitutively increased, yet disease relevant levels of a wild type human p75TNF-R. ${ }^{97}$ These transgenic mice carry the entire genomic region of the human p75TNF-R gene, and expression analysis has revealed that tissue patterns of transgene expression were comparable to those seen for the endogenous murine p75TNF-R. Furthermore, fold induction in the levels of wild type versus transgenic soluble human p75TNF-R, correlated with increases in the levels of the sp75TNF-R between healthy and diseased human sera. It is important to note that heterozygous transgenic mice producing constitutively, threefold to fourfold higher levels of soluble hup75TNF-R in comparison with controls, develop a chronic perivascular inflammatory pathology in the liver, pancreas and lung at 2-3 months of age. Moreover, homozygous mice producing constitutively soluble hup75TNF-Rs at levels similar to those seen for the endogenous murine p75TNF-R in LPS treated normal mice (that is, about $200 \mathrm{ng} / \mathrm{ml}$ ), develop a severe pathology characterised by multi-organ inflammatory lesions, and liver and pancreas necrosis, that lead to their premature death between 2 and 4 weeks of age. ${ }^{97}$ These results indicate that the severity of the developing inflammatory phenotypes correlates positively with the levels of soluble human p75TNF-R measured in diseased sera. Interestingly, serum sp75TNF-R levels measured in several human inflammatory diseases, including AIDS, are usually threefold to fourfold increased over normal controls, ${ }^{98}$ while septic shock patients display an approximately fivefold increase. ${ }^{99}$ In addition, these levels strongly correlate with the clinical stage 
and the progression of disease and can be of predictive value. ${ }^{100}$

With reference to human disease, a plethora of studies have indicated that chronic increased production of the soluble p75TNF-R demarcates fatal human inflammatory conditions including sepsis, ${ }^{99}$ chronic viral hepatic diseases, ${ }^{101}$ acute respiratory distress syndrome, ${ }^{102}$ acute pancreatitis, ${ }^{103}$ lupus, ${ }^{104}$ rheumatoid arthritis $^{105}$ and AIDS. ${ }^{98}$ The actual involvement of soluble TNF receptors in disease pathogenesis remains controversial and it has been suggested that they may act both as antagonists of TNF action by competing with its cell surface receptors but also as agonists by protecting TNF from degradation and therefore stabilising its activity. ${ }^{78}$ In addition, shedding of both TNF receptors occurs in both a constitutive and inducible manner and is thought to serve in rendering cells temporarily unresponsive to $\mathrm{TNF}^{78}$ It is conceivable, however, that sustained upregulation of the p75TNF-R may lead to both, an increase of shed soluble receptors levels, but also to a chronic accumulation of the receptor on the cell surface. We have confirmed this hypothesis both in the transgenic system of p75TNF-R overexpression, ${ }^{97}$ but most importantly also in a group of septic patients, where we have recently detected a parallel upregulation of the soluble p75TNF-R in their sera and of the membrane bound form of this receptor on their peripheral blood mononuclear cells. It is therefore evident that increased levels of shed p75TNF-Rs, as reported in human disease, reflect a similar upregulation of the membrane bound form of the receptor that may consequently interfere with immune homeostasis and disease pathogenesis. Importantly, also, sustained upregulation of the p75TNF-R during human disease may not be accompanied by chronically increased levels of TNF. Indeed, in a recent study investigating kinetics of soluble TNF-R production after leakage of high doses of TNF in the circulation of patients undergoing isolated limp perfusion treatment, it has been observed that levels of soluble p75TNF-R remain high, long after TNF disappears from the circulation, indicating regulatory and perhaps also functional disengagement from TNF. $^{106}$

Interestingly, the lethal inflammatory phenotype developing in the hup75TNF-R transgenic mice is shown to evolve independently of the presence of TNF, LT $\alpha$, or the p55TNF-R. ${ }^{97}$ This finding suggests a physiologically significant role for ligand independent signalling of the p75TNF-R, a receptor known to be strongly induced during the course of an inflammatory response. ${ }^{107}$ There is substantial evidence in vitro, that induced production of members of the TNF-R family, such as the p75 ${ }^{108} 109$ or the p55TNF-R, ${ }^{110}$ Fas, ${ }^{110}$ CD40, ${ }^{108} 111$ or the 75 NGF-R ${ }^{112}$ may lead to spontaneous signalling even in the absence of ligand. The in vivo relevance of this phenomenon, especially for the p75TNF-R, may be of pivotal importance in many clinical conditions including sepsis. Notably, although the $\mathrm{TNF} /$ p55TNF-R system seems to operate only in an initial narrow window of time during clinical sepsis, ${ }^{113}$ soluble p75TNF-R levels are found constantly increased, correlate with sepsis scores and show maximal values in patients that do not survive. ${ }^{99}$ After the disappointing outcome of anti-TNF trials in sepsis, it is tempting to speculate that the increased mortality seen specifically in patients treated with a soluble p75TNF-R-IgG protein, ${ }^{114}$ may have been attributable to an agonistic effect of this specific construct on the endogenous cell surface $\mathrm{p} 75 \mathrm{TNF}-\mathrm{R}$ either by interference with the shedding of this receptor or by mounting an agonistic humoral immune response. Taking into account the observed adverse effects of enhanced p75TNF-R production in transgenic mice, it is conceivable that strategies aiming at inhibiting induced self association or constitutive signalling of this receptor may offer new opportunities of interfering therapeutically with its putative harmful involvement in disease pathogenesis.

1 Vassalli P. The pathophysiology of tumor necrosis factors. Annu Rev Immunol 1992;10:411-52.

2 Vandenabeele P, Declercq W, Beyaert R, Fiers W. Two tumor necrosis factor receptors: structure and function. Trends Cell Biol 1995;5:392-9.

3 Grell $\mathrm{M}$, Douni E, Wajant $\mathrm{H}$, et al. The transmembrane form of tumor necrosis factor is the prime activating ligand of the $80 \mathrm{kDa}$ tumor necrosis factor receptor. Cell 1995;83:793-802.

4 Feldmann M, Brennan FM, Maini RN. Role of cytokines in rheumatoid arthritis. Annu Rev Immunol 1996;14:397440.

5 Stastny P. HLA-D and Ia antigens in rheumatoid arthritis and systemic lupus erythematosus. Arthritis Rheum 1978; 21:S139-43

6 Moreland LW, Pratt PW, Mayes MD, et al. Double-blind, placebo-controlled multicenter trial using chimeric monoclonal anti-CD4 antibody, cM-T412, in rheumatoid arthritis patients receiving concomitant methotrexate. Arthritis tis patients receiving con

7 Olsen NJ, Brooks RH, Cush JJ, et al. A double-blind, placebo-controlled study of anti-CD 5 immunoconjugate in patients with rheumatoid arthritis. The Xoma RA Investigator Group. Arthritis Rheum 1996;39:1102-8.

8 Goldschmidt TJ, Holmdahl R. Anti-T cell receptor antibody treatment of rats with established autologous collagen-induced arthritis: suppression of arthritis without reduction of anti-type II collagen autoantibody levels. Eur J Immunol 1991;21:1327-30.

9 Chiocchia G, Boissier MC, Fournier C. Therapy against murine collagen-induced arthritis with $\mathrm{T}$ cell receptor $\mathrm{V}$ beta-specific antibodies. Eur J Immunol 1991;21:2899905.

10 Holmdahl R, Klareskog L, Rubin K, Larsson E, Wigzell H. $\mathrm{T}$ lymphocytes in collagen II-induced arthritis in mice. T lymphocytes in collagen II-induced arthritis in mice. Characterization of arthritogenic collagen II-specific T-cell
lines and clones. Scand J Immunol 1985;22:295-306.

11 Tada Y, Ho A, Koh DR, Mak TW. Collagen-induced arthritis in CD4- or CD8-deficient mice: CD8+ T cells play a role in initiation and regulate recovery phase of collageninduced arthritis. J Immunol 1996;156:4520-6.

12 Plows D, Kontogeorgos G, Kollias G. Mice lacking mature $\mathrm{T}$ and $\mathrm{B}$ lymphocytes develop arthritic lesions after immunization with type II collagen. J Immunol 1999;162:101823.

13 Mori L, Iselin S, De Libero G, Lesslauer W. Attenuation of collagen-induced arthritis in $55-\mathrm{kDa}$ TNF receptor type 1 (TNFR1)-IgG1-treated and TNFR1-deficient mice. J Immunol 1996;157:3178-82.

14 Kuiper S, Joosten LA, Bendele AM, et al. Different roles of tumour necrosis factor alpha and interleukin 1 in murine tumour necrosis factor alpha and interleukin 1 in murine
streptococcal cell wall arthritis. Cytokine 1998;10:690strep

15 Keffer J, Probert L, Cazlaris H, et al. Transgenic mice expressing human tumour necrosis factor: a predictive genetic model of arthritis. EMBO J 1991;10:4025-31.

16 Kontoyiannis D, Pasparakis M, Pizarro TT, Cominelli F, Kollias G. Impaired on/off regulation of TNF biosynthesis in mice lacking TNF AU- rich elements: implications for oint and gut-associated immunopathologies. Immunity 1999;10:387-98.

17 Probert L, Plows D, Kontogeorgos G, Kollias G. The type I interleukin-1 receptor acts in series with tumor necrosis factor (TNF) to induce arthritis in TNF-transgenic mice. Eur J Immunol 1995;25:1794-7.

18 Katsikis PD, Chu CQ, Brennan FM, Maini RN, Feldmann M. Immunoregulatory role of interleukin 10 in rheumatoid arthritis. J Exp Med 1994;179:1517-27.

19 Miossec P, Naviliat M, Dupuy dA, Sany J, Banchereau J. Low levels of interleukin- 4 and high levels of transforming 
growth factor beta in rheumatoid synovitis. Arthritis Rheum 1990;33:1180-7.

20 Bessis N, Chiocchia G, Kollias G, et al. Modulation of proinflammatory cytokine production in tumour necrosis factor-alpha (TNF-alpha)-transgenic mice by treatmen with cells engineered to secrete IL-4, IL-10 or IL-13. Clin Exp Immunol 1998;111:391-6.

21 Douni E, Akassoglou K, Alexopoulou L, et al. Transgenic and knockout analyses of the role of TNF in immune regulation and disease pathogenesis. J Inflamm 1995;47:27-38.

22 Geiler T, Kriegsmann J, Keyszer GM, Gay RE, Gay S. A new model for rheumatoid arthritis generated by engraftment of rheumatoid synovial tissue and normal human cartilage into SCID mice. Arthritis Rheum 1994;37:1664-71.

23 Muller-Ladner U, Kriegsmann J, Franklin BN, et al. Synovial fibroblasts of patients with rheumatoid arthritis attach to and invade normal human cartilage when
engrafted into SCID mice. Am J Pathol 1996;149:160715.

24 Butler DM, Piccoli DS, Hart PH, Hamilton JA. Stimulation of human synovial fibroblast DNA synthesis by recombinant human cytokines. J Rheumatol 1988;15:1463-70.

25 Dayer JM, Beutler B, Cerami A. Cachectin/tumor necrosis factor stimulates collagenase and prostaglandin E2 producfactor stimulates collagenase and prostaglandin E2 production by human synovial
Med 1985;162:2163-8.

26 Rathanaswami P, Hachicha M, Wong WL, Schall TJ McColl SR. Synergistic effect of interleukin-1 beta and tumor necrosis factor alpha on interleukin- 8 gene expression in synovial fibroblasts. Evidence that interleukin- 8 is the major neutrophil-activating chemokine released in response to monokine activation. Arthritis Rheum 1993; 36:1295-304.

27 Firestein GS. Starving the synovium: angiogenesis and inflammation in rheumatoid arthritis. J Clin Invest 1999;103:3-4.

28 Neurath MF, Fuss I, Pasparakis M, et al. Predominant pathogenic role of tumor necrosis factor in experimental colitis in mice. Eur J Immunol 1997;27:1743-50.

29 Powrie F, Leach MW, Mauze S, Menon S, Caddle LB, Coffman RL. Inhibition of Th1 responses prevents inflammatory bowel disease in scid mice reconstituted with CD45RBhi CD4+ T cells. Immunity 1994;1:553-62.

30 Watkins PE, Warren BF, Stephens S, Ward P, Foulkes R. Treatment of ulcerative colitis in the cottontop tamarin using antibody to tumour necrosis factor alpha. Gut 1997; using antib

31 Targan SR, Hanauer SB, van Deventer SJ, et al. A short-term study of chimeric monoclonal antibody cA2 to tumor necrosis factor alpha for Crohn's disease. Crohn's Disease cA2 Study Group. N Engl J Med 1997;337:102935.

32 Podolsky DK. Inflammatory bowel disease (1). N Engl J Med 1991;325:928-37.

33 van Deventer SJ. Tumour necrosis factor and Crohn's disease. Gut 1997;40:443-8.

34 Kaiser GC, Polk DB. Tumor necrosis factor alpha regulates proliferation in a mouse intestinal cell line. Gastroenterolproliferation in a mouse

35 Heyman M, Darmon N, Dupont C, et al. Mononuclear cells from infants allergic to cow's milk secrete tumor necrosis factor alpha, altering

36 Pender SL, Fell JM, Chamow SM, Ashkenazi A, MacDonald TT. A p55 TNF receptor immunoadhesin prevents T cell-mediated intestinal injury by inhibiting matrix metalloproteinase production. J.Immunol 1998;160:4098-103.

37 Piguet PF, Vesin C, Guo J, Donati Y, Barazzone C. TNF-induced enterocyte apoptosis in mice is mediated by the TNF receptor 1 and does not require p53. Eur J Immunol 1998;28:3499-505.

38 Flory CM, Jones ML, Miller BF, Warren JS. Regulatory roles of tumor necrosis factor-alpha and interleukin-1 beta in monocyte chemoattractant protein-1-mediated pulmonary granuloma $1995 ; 146: 450-62$.

39 Sankey EA, Dhillon AP, Anthony A, et al. Early mucosal changes in Crohn's disease. Gut 1993;34:375-81.

40 Rudin W, Eugster HP, Bordmann G, et al. Resistance to cerebral malaria in tumor necrosis factor-alpha/beta- deficien mice is associated with a reduction of intercellular adhesion molecule-1 up-regulation and $\mathrm{T}$ helper type 1 response. Am J Pathol 1997;150:257-66.

41 Zhan Y, Cheers C. Control of IL-12 and IFN-gamma production in response to live or dead bacteria by TNF and other factors. J Immunol 1998;161:1447-53.

42 Mencacci A, Cenci E, Del Sero G, et al. Defective co-stimulation and impaired Th1 development in tumor necrosis factor/lymphotoxin-alpha double-deficient mice infected with Candida albicans. Int Immunol 1998;10:3748.

43 Shibuya K, Robinson D, Zonin F, et al. IL-1 alpha and TNF-alpha are required for IL-12-induced development of Th1 cells producing high levels of IFN-gamma in BALB/c but not C57BL/6 mice. J Immunol 1998;160:1708-16.

44 Becher B, Blain M, Giacomini PS, Antel JP. Inhibition of Th1 polarization by soluble TNF receptor is dependent on antigen-presenting cell-derived IL-12. J Immunol 1999; $162: 684-8$

45 Strober W, Kelsall B, Fuss I, et al. Reciprocal IFN-gamma and TGF-beta responses regulate the occurrence of mucosal inflammation. Immunol Today 1997;18:61-4
46 Plevy SE, Landers CJ, Prehn J, et al. A role for TNF-alpha and mucosal T helper-1 cytokines in the pathogenesis of and mucosal T helper-1 cytokines in the patho

47 Cope AP, Liblau RS, Yang XD, et al. Chronic tumor necrosis factor alters $T$ cell responses by attenuating $T$ cell receptor signaling. J Exp Med 1997;185:1573-84.

48 Zheng L, Fisher G, Miller RE, Peschon J, Lynch DH, Lenardo MJ. Induction of apoptosis in mature T cells by tumour necrosis factor. Nature 1995;377:348-51.

49 Speiser DE, Sebzda E, Ohteki T, et al. Tumor necrosis factor receptor p 55 mediates deletion of peripheral cytotoxic

Strober W, Fuss IJ, Ehrhardt RO, Neurath M, Boirivant M, Ludviksson BR Mucosal immunoregulation and inflammadviksson BR. Mucosal immunoregulation and inflaminflammation. Scand J Immunol 1998;48:453-8.

51 Sharief MK, Hentges R. Association between tumor necrosis factor-alpha and disease progression in patients with multiple sclerosis. N Engl J Med 1991;325:467-72.

52 Hofman FM, Hinton DR, Johnson K, Merrill JE. Tumor necrosis factor identified in multiple sclerosis brain. J Exp Med 1989;170:607-12.

53 Robbins DS, Shirazi Y, Drysdale BE, Lieberman A, Shin HS, Shin ML. Production of cytotoxic factor for oligodendrocytes by stimulated astrocytes. J Immunol 1987; 139:2593-7.

54 Selmaj KW, Raine CS. Tumor necrosis factor mediates myelin and oligodendrocyte damage in vitro. Ann Neurol 1988;23:339-46.

55 Carlos TM, Harlan JM. Leukocyte-endothelial adhesion molecules. Blood 1994;84:2068-101.

56 Philip R, Epstein LB. Tumour necrosis factor as immunomodulator and mediator of monocyte cytotoxicity induced by itself, gamma-interferon and interleukin-1. Nature 1986;323:86-9.

57 Ruddle NH, Bergman CM, McGrath KM, et al. An antibody to lymphotoxin and tumor necrosis factor prevents transfer of experimental allergic encephalomyelitis. J Exp Med 1990;172:1193-200.

58 Baker D, Butler D, Scallon BJ, O’Neill JK, Turk JL, Feldmann $M$. Control of established experimental allergic encephalomyelitis by inhibition of tumor necrosis factor (TNF) activity within the central nervous system using monoclonal antibodies and TNF receptor- immunoglobulin fusion proteins. Eur J Immunol 1994;24:2040-8.

59 Probert L, Keffer J, Corbella P, et al. Wasting, ischemia, and lymphoid abnormalities in mice expressing $\mathrm{T}$ cell- targeted human tumor necrosis factor transgenes. J Immunol 1993; 151:1894-906.

60 Green EA, Eynon EE, Flavell RA. Local expression of TNFalpha in neonatal NOD mice promotes diabetes by enhancing presentation of islet antigens. Immunity 1998;9: 733-43.

61 Probert L, Akassoglou K, Pasparakis M, Kontogeorgos G, Kollias G. Spontaneous inflammatory demyelinating disease in transgenic mice showing central nervous systemspecific expression of tumor necrosis factor alpha. Proc Natl Acad Sci USA 1995;92:11294-8.

62 Akassoglou K, Probert L, Kontogeorgos G, Kollias G. Astrocyte-specific but not neuron-specific transmembrane nervous system of transgenic mice. J Immunol 1997;158: 438-45.

63 Akassoglou K, Bauer J, Kassiotis G, et al. Oligodendrocyte apoptosis and primary demyelination induced by local TNF/p55TNF receptor signaling in the central nervous system of transgenic mice: models for multiple sclerosis with primary oligodendrogliopathy. Am J Pathol 1998;153: $801-13$.

64 Kassiotis G, Bauer J, Akassoglou K, Lassmann H, Kollias G, Probert L. A tumor necrosis factor-induced model of human primary demyelinating diseases develops in immunodeficient mice. Eur J Immunol 1999;29:912-17.

65 Kassiotis G, Pasparakis M, Kollias G, Probert L. TNF accelerates the onset but does not alter the incidence and severity of myelin basic protein-induced experimental
autoimmune encephalomyelitis. Eur J Immunol 1999;29: $774-80$

66 Korner H, Riminton DS, Strickland DH, Lemckert FA, Pollard JD, Sedgwick JD. Critical points of tumor necrosis factor action in central nervous system autoimmune inflammation defined by gene targeting. J Exp Med 1997; 186:1585-90.

67 Sean RD, Korner H, Strickland DH, Lemckert FA, Pollard JD, Sedgwick JD. Challenging cytokine redundancy: inflammatory cell movement and clinical course of experimental autoimmune encephalomyelitis are normal in ymphotoxin-deficient, but not tumor necrosis factordeficient, mice. J Exp Med 1998;187:1517-28.

68 Eugster HP, Frei K, Bachmann R, Bleuthmann H, Lassmann H, Fontana A. Severity of symptoms and demyelination in MOG-induced EAE depends on TNFR1. Eur J Immunol 2999;29:626-32.

69 Shaw MK, Kim C, Hao HW, Chen F, Tse HY. Induction of myelin basic protein-specific experimental autoimmune encephalomyelitis in C57BL/6 mice: mapping of $\mathrm{T}$ cell epitopes and $\mathrm{T}$ cell receptor $\mathrm{V}$ beta gene segment usage. $\mathrm{J}$ Neurosci Res 1996;45:690-9.

70 Fritz RB, Kalvakolanu I. Thymic expression of the golli-myelin basic protein gene in the SJL/J mouse. J Neuroimmunol 1995;57:93-9.

71 Harrington CJ, Paez A, Hunkapiller T, et al. Differential tolerance is induced in $\mathrm{T}$ cells recognizing distinct epitopes of myelin basic protein. Immunity 1998;8:571-80. 
72 Targoni OS, Lehmann PV. Endogenous myelin basic protein inactivates the high avidity T cell repertoire. J Exp Med inactivates the high

73 Cope A, Ettinger R, McDevitt H. The role of TNF alpha and related cytokines in the development and function of the autoreactive T-cell repertoire. Res Immunol 1997;148: 307-12.

74 van Oosten BW, Barkhof F, Truyen L, et al. Increased MRI activity and immune activation in two multiple sclerosis patients treated with the monoclonal anti-tumor necrosis factor antibody cA2. Neurology 1996;47:1531-4.

75 Arnason BGW. International workshop on Th1/Th2: T-cell defferentiation in MS and autoimmunity, Savannah, Georgia: 1- April 1998

76 Llewellyn-Smith N, Lai M, Miller DH, Rudge P, Thompson AJ, Cuzner ML. Effects of anti-CD4 antibody treatment on lymphocyte subsets and stimulated tumor necrosis factor alpha production: a study of 29 multiple sclerosis patients entered into a clinical trial of cM-T412. Neurology 1997;48:810-16.

77 Aggarwal BB, Natarajan K. Tumor necrosis factors: developments during the last decade. Eur Cytokine Netw developments durit

78 Aderka D. The potential biological and clinical significance of the soluble tumor necrosis factor receptors. Cytokine Growth Factor Rev 1996;7:231-40.

79 Yuan J. Transducing signals of life and death. Curr Opin Cell Biol 1997;9:247-51.

80 Pasparakis M, Alexopoulou L, Episkopou V, Kollias G. Immune and inflammatory responses in TNF alphadeficient mice: a critical requirement for TNF alpha in the formation of primary B cell follicles, follicular dendritic cell networks and germinal centers, and in the maturation of the humoral immune response. J Exp Med 1996;184: 1397-411.

81 Le Hir M, Bluethmann H, Kosco-Vilbois MH, et al. Differentiation of follicular dendritic cells and full antibody responses require tumor necrosis factor receptor-1 signalresponses require tumor necrosis factc

82 Rothe J, Lesslauer W, Lotscher H, et al. Mice lacking the tumour necrosis factor receptor 1 are resistant to TNFmediated toxicity but highly susceptible to infection by Lismediated toxicity but highly susceptible to infection
teria monocytogenes. Nature 1993;364:798-802.

83 Pfeffer K, Matsuyama T, Kundig TM, et al. Mice deficient for the $55 \mathrm{kd}$ tumor necrosis factor receptor are resistant to endotoxic shock, yet succumb to L. monocytogenes infection. Cell 1993;73:457-67

84 Nashleanas M, Kanaly S, Scott P. Control of Leishmania major infection in mice lacking TNF receptors. J Immuno 1998; $160: 5506-13$

85 Ruby J, Bluethmann H, Peschon JJ. Antiviral activity of tumor necrosis factor (TNF) is mediated via p55 and p75 TNF receptors. J Exp Med 1997;186:1591-6.

86 Erickson SL, de Sauvage FJ, Kikly K, et al. Decreased sensitivity to tumour-necrosis factor but normal T-cell development in TNF receptor-2-deficient mice. Nature 1994;372: 560-3.

87 Tartaglia LA, Pennica D, Goeddel DV. Ligand passing: the $75-\mathrm{kDa}$ tumor necrosis factor (TNF) receptor recruits TNF for signaling by the

88 Lucas R, Juillard P, Decoster E, et al. Crucial role of tumor necrosis factor (TNF) receptor 2 and membrane- bound TNF in experimental cerebral malaria. Eur J Immuno 1997;27:1719-25.

89 Kusters S, Tiegs G, Alexopoulou L, et al. In vivo evidence for a functional role of both tumor necrosis factor (TNF) receptors and transmembrane TNF in experimental hepatitis. Eur J Immunol 1997;27:2870-5

90 Wang B, Fujisawa H, Zhuang L, et al. Depressed Langerhans cell migration and reduced contact hypersensitivity response in mice lacking TNF receptor $\mathrm{p} 75$. J Immunol 1997; 159:6148-55.

91 Tartaglia LA, Goeddel DV, Reynolds C, et al. Stimulation of human T-cell proliferation by specific activation of the $75-\mathrm{kDa}$ tumor necrosis factor receptor. J Immunol 75-kDa tumor necr

92 Tartaglia LA, Weber RF, Figari IS, Reynolds C, Palladino MAJ, Goeddel DV. The two different receptors for tumor MAJ, Goeddel DV. The two different receptors for tumor necrosis factor mediate distinct cel
Natl Acad Sci USA 1991;88:9292-6.

93 Herbein G, Mahlknecht U, Batliwalla F, et al. Apoptosis of CD8+ $\mathrm{T}$ cells is mediated by macrophages through interaction of HIV gp120 with chemokine receptor CXCR4 Nature 1998:395:189-94.

94 Slowik MR, De Luca LG, Fiers W, Pober JS. Tumor necrosis factor activates human endothelial cells through the p55 tumor necrosis factor receptor but the p75 receptor contributes to activation at low tumor necrosis factor concentration. Am .J Pathol 1993;143:1724-30.

95 Santee SM, Owen-Schaub LB. Human tumor necrosis factor receptor p75/80 (CD120b) gene structure and promoter

96 Grell M, Wajant H, Zimmermann G, Scheurich P. The type 1 receptor $(\mathrm{CD} 120 \mathrm{a})$ is the high-affinity receptor for soluble tumor necrosis factor. Proc Natl Acad Sci USA 1998;95:570-5.

97 Douni E, Kollias G. A critical role of the p75 tumor necrois factor receptor (p75TNF-R) in organ inflammation independent of TNF, lymphotoxin alpha, or the p55TNFR. J Exp Med 1998;188:1343-52.

98 Hober D, Benyoucef S, Delannoy AS, et al. High plasma level of soluble tumor necrosis factor receptor type II sTNFRII) in asymptomatic HIV-1-infected patients. Infection 1996;24:213-17.

99 Schroder J, Stuber F, Gallati H, Schade FU, Kremer B. Pattern of soluble TNF receptors I and II in sepsis. Infection 1995;23:143-8.

100 Diez-Ruiz A, Tilz GP, Zangerle R, Baier-Bitterlich G, Wachter H, Fuchs D. Soluble receptors for tumour necrois factor in clinical laboratory diagnosis. Eur J Haematol 1995;54:1-8.

101 Marinos G, Naoumov NV, Rossol S, et al. Tumor necrosis factor receptors in patients with chronic hepatitis B virus infection. Gastroenterology 1995;108:1453-63.

102 Lucas R, Lou J, Morel DR, Ricou B, Suter PM, Grau GE. TNF receptors in the microvascular pathology of acute respiratory distress syndrome and cerebral malaria. J Leukoc Biol 1997;61:551-8.

103 de Beaux AC, Goldie AS, Ross JA, Carter DC, Fearon KC. Serum concentrations of inflammatory mediators related to organ failure in patients with acute pancreatitis. $\mathrm{Br} \mathrm{J}$ Surg 1996;83:349-53.

104 Gabay C, Cakir N, Moral F, et al. Circulating levels of tumor necrosis factor soluble receptors in systemic lupus erythematosus are significantly higher than in other rheumatic diseases and correlate with disease activity. J Rheumatol 1997;24:303-8.

105 Cope AP, Aderka D, Doherty M, et al. Icreased levels of soluble tumor necrosis factor receptors in the sera and synovial fluid of patients with rheumatic diseases. Arthritis Rheum 1992;35:1160-9

106 Aderka D, Sorkine P, Abu-Abid S, et al. Shedding kinetics of soluble tumor necrosis factor (TNF) receptors after systemic TNF leaking during isolated limb perfusion. Relevance to the pathophysiology of septic shock. J Clin Invest 1998;101:650-9.

107 de Kossodo S, Critico B, Grau GE. Modulation of the transcripts for tumor necrosis factor-alpha and its receptors in vivo. Eur J Immunol 1994;24:769-72

108 Rothe M, Sarma V, Dixit VM, Goeddel DV. TRAF2mediated activation of NF-kappa B by TNF receptor 2 and CD40. Science 1995;269:1424-7.

109 Rao P, Hsu KC, Chao MV. Upregulation of NF-kappa B-dependent gene expression mediated by the p75 tumor necrosis factor receptor. J Interferon Cytokine Res 1995;15:171-7

110 Boldin MP, Mett IL, Varfolomeev EE, et al. Selfassociation of the "death domains" of the p55 tumor necrosis factor (TNF) receptor and Fas/APO1 prompts signaling for TNF and Fas/APO1 effects . J Biol Chem 1995;270:387-91.

111 Cheng G, Baltimore D. TANK, a co-inducer with TRAF2 of TNF- and CD 40L-mediated NF-kappaB activation. Genes Dev 1996;10:963-73

112 Rabizadeh S, Oh J, Zhong LT, et al. Induction of apoptosis by the low-affinity NGF receptor. Science 1993;261: $345-8$

113 Grau GE, Maennel DN. TNF inhibition and sepsissounding a cautionary note. Nat Med 1997;3:1193-5.

114 Fisher CJJ, Agosti JM, Opal SM, et al. Treatment of septic shock with the tumor necrosis factor receptor: $F c$ fusion protein. The Soluble TNF Receptor Sepsis Study Group. N Engl J Med 1996;334:1697-702. 